\title{
AIDS, Clinical Trials on Women
}

National Cancer Institute

\section{Source}

National Cancer Institute. AIDS, Clinical Trials on Women. NCI Thesaurus. Code C15768.

AIDS clinical trials related to females 12 years of age or older. These trials include pregnant women, women at risk of AIDS, female prostitutes, and women who have perinatally transmitted AIDS to a fetus or newborn. 